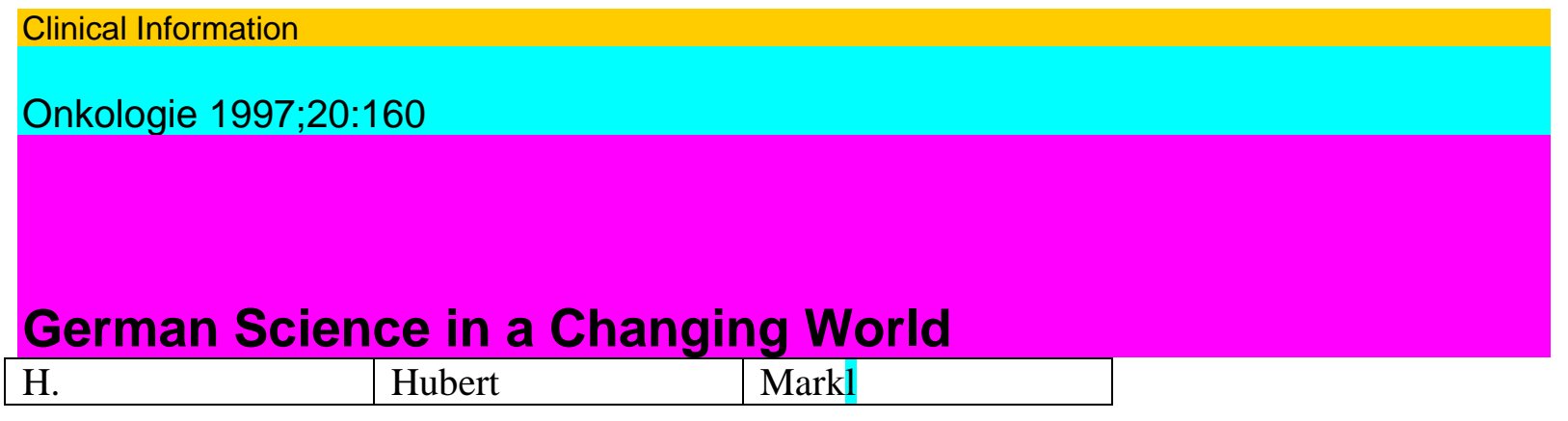

München

Prof. Dr. H. Markl, Präsident der Max-Planck-Gesellschaft, Präsidialbüro, Hofgartenstraße 82, D-80539 München (Germany) It comes as no surprise that Germany, half a decade after the breakdown of a precarious political stability and facing the challenges posed by reunification and global economic markets, is struggling to find its new position in the world. Perhaps spoilt by past success, Germans are learning the hard way that a successful future depends on making the best use of one's innovative talents.

The German higher education system has undergone a hazardous, though necessary, expansion, tripling its size in the past two decades. Harmed by the losses of two world wars and the shameful expulsion or barbarous murder of a sizeable fraction of the nation's elite, the system had not completely recovered before the onset of these reforms. Scientific standards have undoubtedly been compromised; too little care has been taken to ensure that the most talented are given the opportunity to develop in the best of challenging academic environments. Centers of excellence comparable to those in the United Kingdom or the United States are rare in the German university system, and it is urgent that they be strengthened.

Fortunately, the Deutsche Forschungsgemeinschaft (the main grant-awarding agency for research in universities) and the Max-Planck-Gesellschaft (the leading institution for top-quality research) have not followed the egalitarian trend. Both have focused uncompromisingly on evaluation of research and promotion of scientific excellence. The best research centers, within and outside universities, have continued to do first-rate research, in some cases of Nobel Prize quality, and have become truly international enterprises. Few German scientists are now employed without postdoctoral experience abroad, and large numbers of foreign scholars collaborate with their German peers (thanks to the Alexander von Humboldt Foundation, among others). However, there has been criticism, particularly from foreign scientists, that too much authority is often vested in too few men and that gifted young scientists have to wait much too long for full independence. Decisive efforts must be made to deal with these shortcomings; for example, by providing more independent positions and funds for promising younger scholars, particularly women.

In the past, there was no difficulty in attracting students to science and engineering, and highly productive science-based industries gave graduates attractive employment opportunities. The situation has changed alarmingly: Science student enrollment has declined, and unemployment in the science and engineering sectors has risen. It is now of the utmost importance that both academia and industry be shaken out of their self-indulgent complacency. One factor contributing to these depressing trends has been the hostility of a vocal part of German society toward high-tech developments, from nuclear energy to biotechnology. Combined with administrative overregulation, this movement has succeeded only in driving billions of marks worth of high-tech investment abroad. The scientific community has an 
obligation to reverse these trends, not only out of self-interest and responsibility for future generations of scientists, but because such attitudes - form the luddite to the lunatic - are endangering the economic future of the whole country. The best path for science to take is to encourage and support the highest quality and originality in all endeavors and to reform in ways that will realize the potential of the most talented. Adequate funding is a necessary but not sufficient precondition for success, though it is alarming to note that unified Germany has fallen behind major competitors in terms of percentage of gross national product allocated to research and development. However, funds will increase only when the public believes that the autonomy enjoyed by the academic and research community is used to serve the whole society. The spirit scientific innovation could then provide impetus for reform in all sectors of German society. But it must also contribute much more: knowledge and practical solutions to problems facing not only Germans but all of humankind.

Hard choices lie ahead for a Germany that has lived under the illusion that it had a subscription to economic miracles. But in returning from Wonderland to reality, it may yet find itself not too badly placed to exploit the challenging opportunities of this changing world.

Reprinted with permission from Science, Vol. 272, May 10, 1996, p. 791 . Copyright 1996 American Association for the Advancement of Sciences.

\section{KAI \GER}

(c) 1997 S. Karger GmbH, Freiburg Fax (0761) 4520714 http://www.karger.ch 